\title{
Psicologia e Psicanálise numa Instituição de Saúde
}

\author{
Regina Maria Leme Lopes Carvalho ${ }^{1}$ \\ Pontifícia Universidade Católica de Campinas
}

\begin{abstract}
Este artigo apresenta aspectos parciais de uma pesquisa sobre as vivências de uma equipe de psicólogos, orientados teórica e tecnicamente pela psicanálise, trabalhando num hospital infantil. Com base em entrevistas semi-estruturadas, são extraídos os principais temas abordados, os quais se organizam em categorias temáticas. Procura-se discutir, através desse levantamento, as principais preocupações, emoções e formas de agir que caracterizam essa equipe apontando, por meio de variáveis quantitativas, aspectos qualitativos do estudo. Foram levantadas 549 unidades de sentido (u.s.) que se organizaram em 36 variáveis compondo três grandes categorias: Ações, Emoções e Clientela. A categoria das Ações ( $60 \%$ das u.s.) diz respeito ao trabalho institucional e suas características, as das Emoções ( $27 \%$ das u.s.) engloba as vivências pessoais, as emoções, as fantasias e as defesas das entrevistadas e a da Clientela ( $13 \%$ das u.s.) diz respeito às crianças e suas famílias. Com essa distribuição, pode-se ver como se organiza o imaginário desse grupo.

Palavras-Chave: Psicanálise e Instituição, Psicologia Hospitalar, Equipe Multidisciplinar.
\end{abstract}

\begin{abstract}
Psychology and Psychoanalysis in a Health Institution

This article presents partial aspects of a research with a team of psychologists, theoretically and technically oriented by psychoanalysis, working in a children's hospital. The main themes, organized in categories, were extracted from half-structured interviews. The most important worries, emotions and actions that characterizes this team are discussed using quantitative data and trying to observe qualitative aspects of this study. 549 sense units (s.u.) were organized in 36 variants that were grouped in three great categories: Action, Emotion and Clients. Action ( $60 \%$ of the s.u.) is related to the institutional work and its characteristics, Emotion ( $27 \%$ of the u.s.) is related to the personal living experiences, emotions, fantasies and the interviewers defenses and Client ( $13 \%$ of the s.u.) is related to the children and their families. The analyze of this distribution indicate how does this group's imaginary is organized.

Key words: Psychoanalysis and Institution, Psychology Medical, Multidisciplinary Team.
\end{abstract}

\section{Introdução}

A expansão do campo de ação da psicologia clínica para além dos consultórios é um acontecimento que vem se dando com tal intensidade que passou a fazer parte das inquietações dos profissionais desta área, nesses últimos anos. Tradicionalmente, a prática psicológica

1. Professora Doutora do Departamento de Pós-Graduação do Instituto de Psicologia da Puccamp.

Endereço para correspondência: Rua Santa Mônica, 20, Jardim Santa Marcelina, CEP 13094-531, Campinas, SP. e-mail: acarvalho@dglnet.com.br

Apoio da CEAP através dos bolsistas de iniciação cientifica: Cláudia Rezende da Silva, Marcelo Michelson, Michelle Cristine de Miranda Cuoco. clínica mostrava-se como um sistema de atenção voltada para o indivíduo. Como se pode ler no livro Psicólogo Brasileiro (1994), produzido pelo Conselho Federal de Psicologia no intuito de rever as atuais práticas emergentes, muito se tem escrito sobre o tradicional método de se inclinar (kliné, gr.) sobre o paciente para escutar suas queixas e ajudá-lo com nosso saber.

Esse modo "tradicional" ou "clássico", de agir constituiu-se em um momento muito importante de nossa ciência uma vez que lançou os alicerces da teoria e da prática, delimitou o campo de ação e deu os parâmetros para a formação profissional. Assim aconteceu com a 
Psicologia e assim se deu, mutatis mutandi, com a Psicanálise. Fazem parte desse fazer clínico clássico as atividades atribuídas por lei aos psicólogos: o psicodiagnóstico e a psicoterapia individual ou grupal. O psicólogo clínico tendia a ver o seu paciente como um sujeito em si, centrado em seus processos psicológicos, sem se preocupar com seu contexto social e histórico e, por contaminação com o modelo médico, a autoridade do profissional psicólogo ficava incontestada. Toda essa atividade era exercida por um profissional liberal ou autônomo, em consultórios particulares, o que restringia o atendimento às poucas pessoas que lá podiam ir, o que não é só uma questão de dinheiro, mas de toda uma conscientização pessoal. Essa situação perdurou por duas décadas, mais ou menos, desde a regulamentação da profissão em 1962 até o momento em que começaram as demandas institucionais e sociais para que o psicólogo clínico se aliasse à equipe multidisciplinar, principalmente à equipe de saúde. Em outro momento (Carvalho, 1995), mostramos como essa situação se fez sentir também no âmbito das Universidades que, de uma forma ou de outra, mantinham o status quo, uma vez que seus cursos e as oportunidades de estágio que forneciam, seguiam a linha clássica.

A demanda para que o "contexto social" fosse considerado passou a fazer parte das muitas considerações da Psicologia clínica, talvez porque a demanda pelo trabalho em consultórios particulares também tenha se modificado. Entretanto, "contexto social", para a psicologia social, diz respeito à "influência das variáveis socioeconômicas e de classe" (Psicólogo Brasileiro, pg. 12), entendido como variáveis que vêm ao encontro do indivíduo, partindo do ambiente, num movimento de fora para dentro. Já para o psicólogo clínico, "contexto social" pode ter um outro entendimento, vale dizer, aqueles aspectos constitutivos do próprio sujeito que têm origem na sua relação com o outro-social, dentro dele mesmo e que podem ou não sofrer influência de movimentos de pressão, vindos do exterior.

Entretanto, mesmo lidando com o "contexto social" dentro de seu próprio entendimento, o psicólogo clínico vive se confrontando com novas situações profissionais, advindas em parte da própria expansão da profissão, como por exemplo, o atendimento às populações de baixa renda. Como lidar com pessoas que não sabem que podem falar do seu sofrimento e serem ouvidas e acolhidas num Serviço de Saúde, por exemplo? Como lidar com pessoas que nem sequer sabem formular um pedido que pudesse dar conta de sua demanda? (Carvalho, 1987). O psicólogo clínico, viu-se levado a reformular o seu saber, a procurar repensar certas posições teórico/práticas, de forma a auxiliá-lo na percepção dos sujeitos individuais "a partir da experiência vivida em função da inserção social" (Psicólogo Brasileiro, pg. 13). Creio que esse repensar vale para qualquer forma de atuação psicológica: clínica, escolar, do trabalho etc., na medida em que os seres humanos se tornam diferentes dependendo do seu contexto social, mas que é necessário aprender a se aproximar e a ouvir qualquer ser humano, não importa o contexto social no qual ele se encontre. O psicólogo clínico passa a ser convidado a usar o seu método específico centrado no enfoque pessoal, inclinado sobre o indivíduo, mas sobre um indivíduo dentro de um contexto. Quando este contexto é uma instituição, o psicólogo clínico pode passar a fazer parte de uma equipe multidisciplinar trabalhando dentro de instituições de saúde, escolares, de reabilitação, penais, judiciais, da universidade, de associações de classe etc.

Convém lembrar que o psicólogo clínico não é uma entidade abstrata, com características gerais próprias, muito bem definidas e constantes, 
que apenas estaria fazendo uma mudança para um novo ambiente de trabalho. Na realidade, essa categoria - psicólogo clínico- é composta de indivíduos com as mais diversas formações teórico-práticas que se possa imaginar. Ampliar o seu campo de trabalho significa questionar as suas bases teóricas e técnicas para tentar lidar com novas situações. Todas as correntes teóricas, de uma certa forma, são chamadas a responder a esse desafio.

No Brasil, uma grande parte, talvez, a maior parte da formação clínica vem se fazendo sob o enfoque teórico/ técnico da Psicanálise; disto decorrem várias questões que valem a pena examinar neste momento. A primeira delas diz respeito a se a Psicanálise se dirige apenas ao estudo do psiquismo individual - e aí não teria nada a dizer ao contexto social ou se também se dedicaria a examinar os processos psíquicos dos indivíduos nos grupos $\mathrm{e}$ até do próprio grupo. É claro que a segunda colocação é verdadeira, bastando para isso examinar algumas obras bem conhecidas de Freud como Totem e Tabú (1913), O Mal Estar na Civilização (1930), Moisés e o Monoteismo (1939) e outros.

Pensando em todas essas coisas, procurou-se desenvolver uma linha de estudos e pesquisas cuja questão central é a da relação entre os psicanalistas, os psicólogos de formação psicanalítica e as Instituições nas quais trabalham. Atualmente há um crescente número desses profissionais trabalhando ou assessorando hospitais, postos de saúde, secretarias municipais, escolas, associações de bairro e de classe. O que eles têm feito e como agem no seu trabalho é a indagação formulada pela pergunta disparadora das entrevistas.

Essa pesquisa foi levada a cabo graças à colaboração de toda uma equipe de profissionais que trabalham num hospital para crianças e adolescentes. Uma parte dela, a que apresenta os resultados segundo um enfoque de macro-temas - Instituição, Psicanálise e Dinamismos Psíquicos —, já foi publicada (Carvalho,1995). Agora apresentamos os resultados vistos por um ângulo mais quantitativo, explorando uma outra vertente possibilitada pelas técnicas qualitativas de pesquisa, que é a análise dos temas agrupados em categorias, e as relações destas entre si.

O objeto do trabalho é a análise da experiência profissional de psicólogos entrevistados, veiculada pelo seu discurso e pela observação do pesquisador.

O objetivo da pesquisa é o de conhecer as experiências vividas por psicólogos trabalhando em equipes multidisciplinares de saúde em instituições, descrevê-las, analisá-las e propor algumas hipóteses interpretativas.

Os sujeitos da pesquisa foram: cinco psicólogas que formam a equipe psicológica de um hospital dedicado ao atendimento de crianças e adolescentes.

A técnica empregada foi a da entrevista clínica psicológica, aproximando-se ao modelo proposto por J. Bleger (1967) para as "entrevistas livres". Nesse tipo de entrevista, após ter sido colocado o motivo e o tema do encontro, o entrevistador deixa o campo livre para que o entrevistado o organize como quiser. Cabe ao entrevistador observar como se estrutura e se organiza essa interação, ficando atento aos movimentos transferenciais e contratransferenciais. As intervenções do entrevistador limitar-se-ão à busca de elucidações para pontos que possam ficar obscuros.

Essa técnica é geralmente usada para os primeiros contatos clínicos e, no campo da pesquisa psicológica, tem se mostrado de grande utilidade, uma vez que permite ao pesquisador aproximar-se mais do objeto da sua pesquisa o qual, geralmente, é a realidade psíquica de uma outra pessoa ou de um grupo de pessoas. 


\section{Procedimentos}

Procedeu-se da seguinte maneira: em primeiro lugar procuramos entrar em contato com a coordenação da Equipe Psicológica do Hospital para esclarecer e precisar aspectos da pesquisa. Em seguida, foram agendadas entrevistas individuais com cada membro da Equipe em dia, hora e local mais convenientes para ambas as partes.

Esclareceu-se que as entrevistas seriam gravadas e teriam cerca de uma hora de duração. Procurou-se um lugar reservado, calmo, onde se pudesse conversar confortavelmente e onde o sigilo pudesse ser mantido. Esclarecimentos quanto ao sigilo são de grande importância para que a pesquisa possa se desenvolver em clima de confiança e amistosidade. Todos os nomes pessoais foram omitidos bem como o da Instituição.

Esclareceu-se também que de acordo com o projeto pretendia-se conversar com todos os membros da Equipe, mas que a opção de participar ou não da pesquisa era livre.

Uma vez tendo conseguido a concordância do entrevistado, foi feita a seguinte colocação, considerada por nós como uma "pergunta disparadora" da conversa: "Gostaria que você conversasse comigo sobre suas vivências como psicólogo, cuja formação profissional tem sido de base psicanalítica, trabalhando numa Instituição".

O material da pesquisa foi constituído pelo conteúdo das entrevistas, transcrito das fitas e redigido em português. O texto escrito da entrevista, assim obtido, foi comparado mais uma vez com o texto oral gravado nas fitas para que houvesse o máximo de fidelidade entre ambos. Nessa fase é importante assinalar as pausas, reticências, entonações de voz, ênfases em alguns trechos e também acrescentar de memória tudo aquilo que foi percebido, sentido e pensado pelo entrevistador no decorrer do processo. Obtivemos assim um novo texto que foi então analisado segundo os parâmetros propostos para pesquisas qualitativas.

\section{Procedimentos para o levantamento dos dados e análise dos resultados}

No presente estudo, procedeu-se da seguinte forma: após a transcrição das fitas gravadas nas entrevistas, começamos a levantar os temas, seqüência por seqüência. As seqüências ou unidades de significado são segmentos de sentido que configuram o texto. Cada sequiência foi numerada para que pudesse ser encontrada no texto da entrevista. Assim, em cada entrevista, pudemos saber quantas vezes um determinado tema foi abordado e em que contexto. Obtivemos um primeiro resultado da freqüência dos temas por entrevista; a seguir, reunimos os temas semelhantes em todas as entrevistas e obtivemos uma segunda tabela de resultados. À medida que esse levantamento foi sendo feito, apareceu a necessidade de explicitar certos conceitos com os quais estávamos trabalhando implicitamente. Por exemplo, um dos principais temas foi o do TRABALHO, mas o que significa TRABALHO no contexto das entrevistas? Esse significado é o mesmo em todas as entrevistas? Com essa preocupação, passamos a descrever os temas e a categorizá-los, criando as primeiras categorias emergentes dos textos das entrevistas. Nessas categorias, procuramos incluir todos os significados afins e construímos uma nova tabela, que apresentaremos a seguir em ordem decrescente de freqüência.

\section{Resultados}

Categorias Temáticas ( $\mathbf{N}=$ Número de respostas)

1. TRABALHO: $\mathrm{N}=111$

Por "Trabalho" entendemos:

- O papel que cada entrevistada exerce dentro da instituição. 
- Diferenças do Trabalho em Instituição e Consultório.

- Rotina do Trabalho.

- Discordância entre formas de Trabalho.

\section{INSTITUIÇÃO: $\mathbf{N}=\mathbf{5 5}$}

Por "Instituição" entendemos:

- Local organizado, o Hospital, onde as entrevistadas trabalham.

- Um certo sistema organizado de forma clara, mas com momentos de ambigüidade.

- Diferenças de interpretação feitas no consultório e na Instituição.

- Características da Instituição como: alto nível de exigência, lidar com uma realidade penosa.

\section{DIFICULDADE: $\mathbf{N}=\mathbf{4 6}$}

Por "Dificuldade" entendemos:

- A dificuldade em se trabalhar com a equipe (conflitos).

- A dificuldade em lidar com a angústia dos pais e do próprio paciente.

- A própria dificuldade em estar elaborando processo de vida $\mathrm{x}$ morte.

\section{PACIENTES: $\mathbf{N}=\mathbf{4 5}$}

Por "Pacientes" entendemos:

- Quem é o paciente em atendimento?

- As crianças.

- Os seus pais.

- Os adolescentes.

- As suas famílias.

\section{PSICANÁLISE: $\mathbf{N}=\mathbf{3 1}$}

Por "Psicanálise" entendemos:

- É um método que pode fazer o paciente "mudar".

- A psicoterapia psicanalítica.

- Método adequado para se lidar com emoções.
- Um corpo de teorias que possibilita a compreensão de fenômenos psíquicos.

\section{PSICOTERAPIA BREVE: $\mathbf{N}=\mathbf{2 6}$}

Por "Psicoterapia Breve" entendemos:

- Teoria/Técnica específica com tempo marcado e foco definido.

- Terapia Breve de Grupos.

- Discussão sobre se o que elas fazem é T.B. ou não.

7. ADOLESCENTES: $\mathbf{N}=\mathbf{2 6}$

Por "Adolescentes" entendemos:

- Aqueles pacientes com mais de 12 anos e que têm uma forma própria de adoecer.

- Uma clientela específica e que coloca questões.

- Pessoas que têm uma situação típica de sua faixa etária, o que torna a questão vida $\mathrm{x}$ morte crucial.

\section{CONSULTÓRIO: $\mathbf{N}=\mathbf{2 5}$}

Por "Consultório" entendemos:

- Espaço em que as entrevistadas atendem "fora da Instituição".

- Consultório privado, particular.

- Clientela com características próprias: desejam o atendimento psicoterápico.

\section{LIMITE: $\mathbf{N}=\mathbf{2 0}$}

Por "Limite" entendemos:

- A barreira até onde as entrevistadas podem "chegar", até onde a Instituição permite que exerçam o seu trabalho.

- "Limite" para as famílias (UTI).

- Limite para as próprias fantasias em relação à cura, à morte etc.

- Limite para o envolvimento que a Instituição exerce. 


\section{EQUIPE : $\mathbf{N}=19$}

Por "Equipe" entendemos:

- Os profissionais que trabalham multidisciplinarmente dentro da Instituição: Psicólogas, Residentes, Docentes, Enfermeiras, Fisioterapeutas, Musicoterapeutas etc.

- Equipe de outros hospitais.

- A Equipe de Psicologia.

11. MORTE: $\mathbf{N}=\mathbf{1 3}$

Por "Morte" entendemos:

1. "Ações" ligadas ao fato de a morte ocorrer.

- Conflito quanto às condutas na UTI.

- Tipo de Trabalho próprio aos pedidos de socorro.

- Trabalhos com as famílias e os residentes.

- Prognósticos (diagnóstico fechado).

- O "grupo" ajudando a suportar os óbitos.

2. "Emoções" suscitadas pela morte.

- Impotência diante da morte.

- Luta, conflito vida x morte, defesas.

- Compreensão psicanalítica da perda.

- Sair x sucumbir: a psicóloga testemunha do conflito; seu papel é a presença.

12. MEDO: $N=12$

Por "Medo" entendemos:

- Medo de ser interpretada, medo daquilo que quer dizer.

- Medo de se perder diante do processo dinâmico da Instituição.

- Medo do fracasso profissional.

- Medo de mobilizar o paciente e não saber o que fazer.

- Medo de perder o paciente (morte) - encoberto.

- Medo de se expor, da divulgação da entrevista.

13. DOENÇA E DOR: $\mathbf{N}=11$ Por "Doença e Dor" entendemos:

- Doença invasiva, envolvente.
- Negação da doença.

- Conflito entre doença e morte.

- Ação psicológica ajuda a suportar a dor.

14. CONFLITO: $\mathbf{N}=\mathbf{1 0}$

Por "Conflito" entendemos:

- Entre membros da família do paciente.

- Entre "autoridades" da equipe.

- Com a chefia autoritária.

- Rivalidade entre membros dos grupos terapêuticos.

\section{EXPERIÊNCIA - TÉCNICA - CONHE- CIMENTO: $\mathbf{N}=\mathbf{1 0}$}

Por "Experiência" entendemos:

- Falta de experiência profissional.

- Falta de trabalhos na literatura especializada.

- Experiência no exterior ajuda muito.

- Experiência com o psicanalista ajuda.

- Técnicas diferentes, para os diversos grupos.

- Técnica do desenho ajuda as crianças.

16. SUPERVISÃO: $\mathrm{N}=9$

Por "Supervisão" entendemos:

- Técnica de aprendizagem usada pela Equipe.

- Supervisão clínica e Institucional.

- Trabalho com as Estagiárias.

\section{CÂNCER: $\mathbf{N}=8$}

Por "Câncer" entendemos:

- Doença especial - preferem tratamento clínico.

- Resistência ao tratamento psicológico.

- Prognóstico fechado.

- Comparação entre o Cancer e a Equipe.

- Bom prognóstico.

- Instituição é um câncer.

- Câncer na adolescência é contra a própria natureza porque a pessoa perde a autonomia. 


\section{DESEJO: $\mathbf{N}=7$}

Por "Desejo" entendemos as fantasias de:

- Ser psicanalistas.

- Curar, ajudar pessoas.

- Ensinar.

- Diferenças entre o "Desejo" no hospital e no consultório particular.

\section{LUDOTERAPIA: $\mathrm{N}=6$}

Por "Ludoterapia" entendemos:

- Técnica psicoterápica específica.

- Muda o quadro da doença - pode mudar o quadro do câncer.

- Diferenças de técnica e de setting na Instituição.

- Oferece material para supervisão.

- Aumenta o campo da compreensão.

20. RESISTÊNCIA: $\mathbf{N}=\mathbf{5}$

Por "Resistência" entendemos:

- Ao tratamento psicológico.

- É algo próprio dos pais, dos pacientes.

- À alta; paciente recai.

\section{APOIO: $\mathbf{N}=\mathbf{5}$}

Por "Apoio" entendemos:

- Tipos de trabalhos com os pacientes, as famílias e a equipe multidisciplinar.

- Suporte para o trabalho terapêutico para as angústias.

- Método terapêutico diferente da psicanálise.

\section{SATISFAÇÃO: $\mathbf{N}=\mathbf{5}$}

Por "Satisfação" entendemos:

- O resultado positivo que se tem em atender os pacientes e suas famílias que se recuperam.

- Em auxiliar o residente quando este se sente frágil perante a morte.

- Com o trabalho na Instituição.

\section{ANGÚSTIA: $\mathbf{N}=\mathbf{5}$}

Por "Angústia" entendemos:

- A vontade de poder ajudar e sentir as próprias limitações.

- Exigência muito grande causa angústia.

24. DISPONIBILIDADE: $N=\mathbf{5}$

Por "Disponibilidade" entendemos:

- Para o Trabalho.

- Para conter as angústias.

25. EMOÇÕES: $N=4$

Por "Emoções" entendemos:

- Lado emocional do paciente.

- Instituição favorece envolvimento emocional com pacientes.

- Medo de mobilizar emoções.

- Indicação de Terapia Individual para lidar com emoções.

\section{CONSCIÊNCIA : $\mathbf{N}=\mathbf{4}$}

Por "Consciência" entendemos:

- Maior conhecimento e reorganização.

- Entrar em contato com vínculo, doença e morte.

- Como percepção da realidade externa.

\section{EXIGÊNCIA: $\mathbf{N}=4$}

Por "Exigência" entendemos:

- Criou-se um padrão muito alto de exigência que percorre a Instituição da chefia até a entrevistada.

- Clima envolvente de exigência.

- Rigidez de critérios e atitudes (evitar).

28. DÚVIDA: $\mathbf{N}=3$

Por "Dúvida" entendemos:

- Quanto à capacidade profissional - até à competência para o trabalho.

- Quanto à própria competência.

- Quanto ao que mais fazer - como progredir na Instituição. 
29. VÍNCULO: $\mathrm{N}=3$

Por "Vínculo" entendemos:

- Entre os membros da equipe.

- Valor vínculo entre adolescente $\mathrm{x}$ terapeuta.

- Em grupos de adolescentes.

- De apoio e ajuda.

30. CRIANÇA: $\mathbf{N}=\mathbf{3}$

Por "Criança" entendemos:

- "A criança" em geral.

- Como tema de estudo.

- Hospitalizada, adoecida.

\section{RESPEITO: $\mathbf{N}=\mathbf{3}$}

Por "Respeito" entendemos:

- Respeito aos pacientes (como limite).

- Respeito como orgulho do trabalho.

32. FRUSTRAÇÃO: $\mathbf{N}=\mathbf{3}$

Por "Frustração" entendemos:

- Vista como crescimento.

- Levando ao pensamento.

- Vista como sofrimento.

- Não elaborada, vista como decepção com o trabalho.

\section{FANTASIAS: $\mathbf{N}=\mathbf{2}$}

Por "Fantasias" entendemos:

- Fantasias messiânicas - santo milagroso (falta de limite e desejo).

- Fantasia onipotente de controle da doença, de cura.

\section{RESPONSABILIDADE: $\mathrm{N}=\mathbf{2}$}

Por "Responsabilidade" entendemos:

- Em assumir sozinha certas atitudes na Instituição,

- Na substituição de colegas.
35. SOFRIMENTO: $\mathbf{N}=\mathbf{2}$

Por "Sofrimento" entendemos:

- Do paciente.

- Do adolescente.

36. ORGULHO: $\mathrm{N}=1$

Por "Orgulho" entendemos:

- Pela competência pessoal e da equipe.

\section{Discussão}

Análise e Elaboração das

Categorias Temáticas

É uma experiência comum aos pesquisadores que lidam com análise de discurso e pesquisas qualitativas observar a riqueza do material que vai se transformando diante dos olhos, compondo e recompondo redes de significados, como um caleidoscópio sem fim. Isso foi acontecendo nessa experiência à medida que fomos lidando com as categorias, estabelecendo relações entre elas e percebendo que uma nova rede de significados foi aparecendo dentro do conjunto.

Percebemos que as 36 categorias de temas até aqui identificadas poderiam ser reagrupadas em três grandes categorias, a saber: a das AÇÕES, a das EMOÇÕES e a da CLIENTELA. Esses nomes foram dados numa primeira instância podendo vir a serem trocados se um olhar mais aprofundado sobre o conteúdo desses agrupamentos assim o indicar. Assim, apareceu um grupo de categorias temáticas que dizia respeito a formas e a métodos de agir e trabalhar; são elas: o tema Trabalho (o de maior freqüência), que diz respeito exatamente àquilo que fazem quando se consideram trabalhando, e o tema Instituição, que reúne as idéias sobre uma organização funcional operando: o Hospital, que se opõe a um outro tema, o do Consultório, que significa um outro local de 
trabalho, com características diferentes da Instituição. Depois temos Psicanálise, Psicoterapia Breve, Apoio e Ludoterapia, que são temas sobre as diferentes form?s do fazer terapêutico na Instituição. Um outro conjunto de temas mostra aspectos da exigência desse Trabalho e são: Responsabilidade, Experiência e Técnica, Supervisão, Exigência, Equipe. Dois temas foram incluídos nesta categoria das Ações e também na das Emoções, são eles: Dificuldade e Morte. Ficamos bastante surpresas com o fato de o tema Morte aparecer significando, por exemplo, aquilo que precisa ser feito quando há um óbito e por isso o colocamos na grande categoria das Ações. Em outro contexto, o tema Morte tinha outro significado e foi incluído na categoria das Emoções. Com o tema Dificuldades aconteceu a mesma coisa: de um lado, as dificuldades concretas desta ou daquela conduta e, do outro, situações mais afetivas. Essas são as circunstâncias que enriquecem esse tipo de pesquisa e que simultaneamente se tornam um desafio para o pesquisador, na medida em que novas associações vão se fazendo e permitindo que apareçam novos contextos significativos.

Passemos para o segundo grande conjunto de temas, que foi denominado de Emoções. A ele pertencem as seguintes categorias temáticas: Limites (significando respeito ao outro), Conflito, Dificuldade, Satisfação, Angústia, Medo, Frustração, Doença/Dor, Câncer, Resistência, Morte, Dúvida, Disponibilidade/Fé, Fantasias, Desejos, Consciência, Emoções, Vínculo, Rigidez e Orgulho. Todas essas categorias referem-se a estados de mente, ora significando emoções, ora mecanismos de defesa contra a dor psíquica. Essa categoria foi a que reuniu o maior número de temas, o que não é de se espantar, dado o tipo da população examinada. Trabalhar numa Instituição Hospitalar, voltada para o atendimento de crianças e adolescentes portadores de câncer, deve ser algo emocionante em todos os sentidos.

A terceira grande categoria denominada Clientela reúne os temas específicos sobre as crianças, os adolescentes, seus pais e familiares. Geralmente, as entrevistadas gostam de falar sobre as reações que os pacientes e suas famílias têm do fato de virem ao hospital porque estão doentes e todo o tumulto que isso desencadeia. Paralelamente, falam das experiências que os outros membros da Equipe Multidisciplinar têm com a Instituição e de como elas, as psicólogas, lidam com isso. Aqui também incluímos um tema que já apareceu na categoria Emoções: o Sofrimento, porque as entrevistadas destacam muito o sofrimento da clientela, de um modo geral, como mobilizando o pessoal técnico e determinando, de uma certa forma, a organização do atendimento. Foi por observarem e serem sensíveis ao sofrimento próprio dos adolescentes, que várias técnicas de atendimento psicoterápico foram implementadas. Um outro tema interessante é o das Estagiárias, que são parte da clientela da Equipe de Psicologia, uma vez que é essa equipe que propõe e organiza o estágio voluntário de Psicólogas, vindas de diversas universidades, no Hospital. Esse trabalho é muito valorizado e visto com carinho, pelo menos, por três dos cinco membros da Equipe.

É interessante analisar o quadro das categorias temáticas pelas possibilidades de interpretação que ele nos sugere. Em primeiro lugar, tomando por base o agrupamento dos Temas nas três grandes categorias propostas, a das Ações, das Emoções e da Clientela, vemos (como os gráficos nos mostram) a seguinte distribuição: Ações, $60 \%$ de respostas; Emoções, $17 \%$ de respostas; Clientela, $13 \%$ de respostas.

Entretanto, se formos verificar a freqüência de respostas nas categorias temáticas simples, vemos que as maiores incidências são: Trabalho com 111 atribuições e, logo a seguir, 
Instituição com 55 atribuições. Estes dois temas estariam, portanto, apontando as principais preocupações das entrevistadas: a rotina do trabalho, mostrando as diferenças entre instituição e consultório, e o hospital, ora com uma organização clara, ora ambígua, e com um alto nível de exigência para lidar com uma realidade penosa. Logo a seguir vem o tema Dificuldade $(\mathrm{N}=46)$ de trabalhar da forma como o fazem e de elaborar as emoções e os conflitos que esse trabalho suscita.

Do $4^{\circ}$ ao $10^{\circ}$ tema na relação decrescente de categorias temáticas, encontramos temas de Ações e Clientela com uma única exceção que é Limites na $9^{\mathrm{a}}$ colocação.

Daí para frente, até a $36^{\mathrm{a}}$ colocação predominam os temas da categoria Emoções.

Como podemos entender esse panorama? Que idéias ele nos sugere?

Em primeiro lugar, que a equipe parece bastante homogênea quanto as suas percepções sobre o trabalho no hospital. Percebem bem os aspectos positivos e negativos e a tremenda demanda que o lidar com a doença e a morte na infância impõe aos profissionais. Até quanto às dificuldades com os Limites parece haver uma razoável concordância, parecendo ser uma característica própria da instituição e da equipe. Posso também pensar que dado o caráter da pergunta disparadora que quer saber sobre as "vivências" dos profissionais, elas possam ter respondido primeiro ao nível do que está mais consciente e talvez mais organizado, e por isso, menos perigoso, para, em seguida, de uma forma menos coesa, apontar as diversas emoções que permeiam esse trabalho.

Apesar de haver um número grande de categorias que falam das Emoções, a freqüência de respostas dadas é baixa se comparada ao número de referências aos temas, por exemplo: do Trabalho, das Psicoterapias, das Técnicas de Atendimento etc. Sendo uma equipe que diz ter uma formação em psicanálise, pensamos que esse quadro sugere um grupo muito defendido, o que se pode bem compreender, face às exigências das tarefas e pouco livre para deixar vir à tona suas emoções que são muitas (vide a dispersão dessa categoria) e bastante intensas. Em outro momento, discuto (Carvalho 1995) esse assunto com mais amplitude. Agora o meu interesse é mostrar o alcance que uma análise de variáveis/categorias pode ter, dando uma compreensão mais ampla para o assunto estudado, possibilitando uma comparação com outras pesquisas.

\section{Aspectos Circunstanciais Transferenciais e Contra-Transferenciais}

Todo empreendimento de pesquisa tem como base um planejamento teórico e, além disso, lida com vivências pessoais dos pesquisadores e pesquisados e, ainda, com aspectos circunstanciais. Por aspectos circunstânciais entendo a presença de situações da realidade externa que se organizam e, de uma certa forma, delimitam e caracterizam o nosso trabalho. Darei um exemplo: no planejamento da pesquisa, pensamos em fazer as entrevistas no próprio lugar de trabalho das entrevistadas, isto é, no prédio do hospital. As entrevistas no hospital ocasionaram um certo impacto. Não havia exatamente uma sala reservada para elas, uma vez que a sala da Equipe de Psicologia era usada todo o tempo e não pode ficar disponível para o nosso trabalho. Assim, uma das entrevistadas acabou me levando para a Internação, onde havia alguns quartos disponíveis e nos quais poderíamos nos sentar e utilizar o gravador. Essa foi uma circunstância altamente desfavorável e penso que o gravador não funcionou porque eu estava sob o impacto de, no quarto ao lado, crianças estarem à morte. Só quando foi possível usarmos uma das salas de atendimento psicológico é que as entrevistas puderam transcorrer naturalmente. Apesar 
disso, duas entrevistadas preferiram conversar comigo no meu consultório particular.

Ressaltar esse tipo de acontecimentos é muito próprio das pesquisas qualitativas, uma vez que é através deles que se evidenciam os fatores emocionais que percorrem o relacionamento pesquisador-pesquisado.

A Psicanálise propõe, sob o nome de transferência e contra-transferência, a observação da natureza e a direção dos fenômenos que estão em jogo nessa relação, fenômenos que se organizam segundo padrões que se repetem, próprios a cada pessoa, e que se constituíram arcaicamente. A idéia é a de que essas experiências arcaicas presidem a organização do nosso olhar ao entrarmos em contato com situações "novas"; esse novo é visto com olhos "antigos", os nossos olhos habituais. Assim, o observador atento pode vir a conhecer a estrutura que preside a organização mental da pessoa do entrevistado, através das ressonâncias pressentidas em si próprio, que é a contra-transferência.

Por isso, ao viver um processo como este, entramos em contato não só com o tema da pesquisa, com o assunto propriamente dito, mas com as pessoas que com ele colaboraram e conosco mesmos.

A curiosidade - e sem ela como pesquisar? - parece ter sido a emoção que mais nitidamente permeou o contato de ambas as partes. Do meu lado, estava curiosa e impressionada com o ambiente de trabalho no hospital; do outro lado, havia uma certa emoção em serem "sujeitos de pesquisa" e uma certa apreensão com o que estava acontecendo. Entretanto, houve um clima de amistosidade e franqueza, na medida em que relataram, de "peito aberto", suas experiências. Houve apenas uma exceção, na medida em que uma das entrevistadas procurou negar a existência de dificuldades intra-equipe motivadas, principalmente, por disputa e inveja. Pude notar também que algumas foram mais afetuosas comigo, ou seja, lidaram mais livremente com seus afetos incluindo-me, como participante que era, na vivência daquele momento. Outras mantiveram-se distantes, corteses e colaboradoras, mas sinalizando que estavam apenas cumprindo uma tarefa e que nada tinham a ver comigo.

\section{Conclusão}

A análise e a soma das u.s. que se organizaram em variáveis que compõem as categorias mostram o seguinte panorama: as preocupações, os interesses e as questões dirigem-se prioritariamente para o trabalho que a equipe executa no hospital. Estão preocupadas em questionar o seu desenvolvimento profissional e têm uma exigência pessoal e como equipe muito grande nesse sentido.

O que fica evidente é que essa equipe tem uma visão muito positiva do seu trabalho, dedica-se a ele com entusiasmo e "orgulho", como nos disse uma delas, e faz com que ele seja muito significativo para si, para a clientela da instituição e para a comunidade em geral.

Secundariamente, apontam os estados emocionais que permeiam suas ações. Como todo grupo humano, este vive sob tensões emocionais em que inveja e disputa aparecem, mas também angústia, medo, insegurança, continência, disponibilidade e tolerância.

O lugar que a psicanálise como tal ocupa nesse trabalho parece ser duplo, através do levantamento das categorias temáticas. De um lado, é um norteador seguro teórico/profissional que a equipe valoriza e procura utilizar, embora reconhecendo seus próprios limites; do outro, é o apoio terapêutico que dá a continência necessária para o exercício de seu trabalho. Novas pesquisas sobre o tema da interação psicologia, psicanálise e instituições, feitas em outros contextos, poderão trazer contribuições importantes para implementar teoria, técnica e prática nos cursos de formação de psicólogos visando a atuação em equipes multidisciplinares. 


\section{Referências}

Bion, W.R. (1975) Experiências com Grupos (2 edição). Rio de Janeiro, Editora Imago.

Bion, W.R. (1976) Os Elementos da Psicanálise (6 edição) Buenos Aires, Editora Nueva Visión.

Bleger, J. (1976) Temas de Psicologia (entrevista y grupos) (6 $6^{\mathrm{a}}$ edição). Buenos Aires, Editora Nueva Visión.

Carvalho, R.M.L.L. (1992) Ludoterapia Psicanalítica com Crianças e Adolescentes Institucionalizados. Tese de Doutoramento, UNICAMP.

Freud, S. (1913) Totem e Tabu. Edição Standard Brasileira das Obras Completas de Freud, vol. XIII, pp. 13-194, Rio de Janeiro, Editora Imago.

(1930) O Mal Estar na Civilização. Edição Standard Brasileira das Obras Completas de Freud, vol. XXI, pp. 75-171, Rio de Janeiro, Editora Imago, 1974.

(1939) Moisés e o Monoteísmo. Edição Standard Brasileira das Obras Completas de Freud, vol. XXIII, pp. 13 - 164, Rio de Janeiro, Editora Imago, 1974.

Lo Bianco, A. C., Bastos, A. V. B., Nunes, M. L. T., Silva, R. C. de, (1994) Concepções e Atividades Emergentes na Psicologia Clínica: Implicações para a Formação. In: Conselho Federal de Psicologia: Psicólogo Brasileiro: Práticas Emergentes e Desafios para a Formação (pp. 7-79), São Paulo, Casa do Psicólogo.

Mucchielli, A (1991) Les Méthodes Qualitatives ( $1^{\text {a }}$ edição). Presses Universitaires de France. 